\title{
REDUCING CHILDHOOD EXPOSURE TO INDOOR AIR POLLUTION: THE POTENTIAL ROLE OF BEHAVIOUR CHANGE INTERVENTIONS
}

\author{
BRENDON BARNES* \& ANGELA MATHEE \\ *South African Medical Research Council, Health and Development Group, P. O. Box \\ 87373, Houghton, 2041, mail to: bbarnes@ mrc.ac.za
}

\section{INTRODUCTION}

Indoor Air Pollution (IAP) accounts for the deaths of millions of children each year (1).

In 1999, experts in the study of IAP convened in Washington D. C. to discuss, amongst other things, ways to prevent or reduce childhood exposure to IAP.

To date, prevention interventions have been dominated by large-scale technical interventions, which have proven to be costly (to the user and implementing agency) and unsustainable. At the end of this meeting, the question was posed:

"When it comes to indoor air pollution, how can we improve people's health without necessarily increasing their wealth?

The aims of this paper, therefore, are:

- To offer insight into why behaviour change as an intervention might be able to inform that question.

- To present a study currently being conducted in South Africa to determine the effects of a behavioural intervention to reduce child exposure to indoor air pollution.

\section{INDOOR AIR POLLUTION}

Indoor air pollution arises from the burning of biomass fuels (wood, dung and crop residues), charcoal and paraffin in open fires or poorly functioning stoves (1). Approximately half the world's population and up to $90 \%$ of rural households in developing countries still rely on biomass fuels such as wood, animal dung and crop residues (2) for activities such as cooking, space heating and water heating.

The pollutants produced by the combustion of these fuels include particulate matter $\left(\mathrm{PM}_{10}\right.$ and $\mathrm{PM}_{2.5}$ ), carbon monoxide (CO), sulphur dioxide $\left(\mathrm{SO}_{2}\right)$ and nitrous oxides (NOx).

Women, who typically spend most of their time around the burning area, are exposed tohigh levels of pollution for up to 3-7 hours a day over many years (3). In some instances, this exposure is 2 to
4 times more than men (4). Young children are often in close proximity to mother's/caregivers throughout the day (5) either on their own or are carried on mothers' backs (6). In this way, they are also exposed to high levels of IAP.

A number of health outcomes have been associated exposure to IAP. In particular, acute lower respiratory infections (ALRIs) such as pneumonia have been identified as a major health effect of exposure to IAP (7).

Recent estimates indicate that ALRIs account for approximately $33 \%$ of all deaths of infectious disease globally and $27 \%$ of the entire burden of infectious diseases, of which, $80 \%$ occurs in children under 5 years of age in developing countries (8).

In South Africa, estimates indicate that infant mortality rates due to ALRIs are, at a minimum, 7 times greater than those recorded in Western European countries (9).

A number of studies have shown a relationship between ALRIs and indoor air pollution arising from the use of wood, coal and paraffin in South Africa. As early as 1982, Kossove (10) found that over $70 \%$ of infants less than 13 months of age with severe lower respiratory tract infections had a history of daily wood smoke exposure from cooking and heating fires. This was significantly higher than infants studied in the "non respiratory problem' group.

Similarly, the Vaal Triangle Air Pollution Health study found that the use of coal for cooking and heating was the most significant risk factor for the development of respiratory illness in children. Children living in homes using coal had a 9.3 times higher risk of developing respiratory illness compared to children living in homes using electricity (11).

A recent study showed that paraffin was the most commonly used alternative to electricity. It showed that a significant number of homes had levels of pollutants $\left(\mathrm{CO}, \mathrm{NO}_{2}\right.$ and $\left.\mathrm{SO}_{2}\right)$ above international guidelines (12). 
Overall, the fuels people use become cheaper, more accessible and cleaner (i.e. more beneficial to health) as people move up the 'energy ladder'. Animal dung is at the lowest rung of the ladder. As one moves up the ladder, animal dung is succeeded by crop residues, wood, coal, kerosene, gas and electricity, with electricity being the cleanest yet most expensive (2).

Fuel use, it seems, is directly linked to socioeconomic status. This has important implications for types of interventions used to reduce exposure to IAP.

\section{BEHAVIOUR CHANGE AS A PREVENTION INTERVENTION}

Globally, interventions to reduce exposure to IAP have been largely 'technical' in nature. Interventions have either focused on improvement of existing appliances (e.g. the provision of improved chimneys), the introduction of new technologies (e.g. new braziers for space heating) or the promotion of cleaner, more efficient fuels (e.g. electricity).

The latter type of intervention has been given prominence. In particular, electrification has been highlighted because of it's potential for improving health.

However, many of these technical interventions have proven to be unsustainable largely because of the cost implications for the user.

For example, in South Africa, several years after being supplied with electricity, households may continue to use multiple fuels for various tasks. Research has shown that in practice, households commonly use electricity for lighting, refrigeration and entertainment (television sets, music centres, video machines and radios), but less so for cooking and space heating, which have the greatest implications for indoor air pollution and respiratory health outcomes.

In a survey conducted in Sebokeng, continuing use of coal for space heating and cooking was reported for $48 \%$ and $45 \%$ of electrified households respectively (11). A recent study (5) in a rural South African village indicated that, although electricity was used almost immediately for lighting, there was considerable delay in the use of electricity for purposes such as cooking and space heating. Approximately 4 years after being supplied with electricity, $89 \%$ of the households reported that electricity had never been used for space heating and in $61 \%$ of the households had never used an electrical stove.

A number of reasons have been put forward to explain the delay in the transition from solid and liquid fuels, up the 'energy ladder', to the exclusive use of electricity. Studies suggest that the primary reason for the continued use of solid and liquid fuels is that the poor do not have the financial resources to use electricity exclusively for all end uses (13)(14) (2). Irregular, low and in some cases, non-existent household income, necessitate energy use patterns that can cope with this. Electricity is relatively expensive and can account for a significant portion of a low-income household's expenditure. In addition, the secondary costs of electrical appliances become an extra burden on household limited financial resources (15).

Banks, Mlomo and Lujabe (16) have also identified certain social, cultural determinants as important reasons for the delay in the use of electricity. For example, studies have thus far indicated that people often equated the cooking with wood and/ or coal as a having particular cultural significance. Wood and coal has always played a role in bringing the family together in the evenings. Families would sit around indoor fires and exchange stories about the day. Fire is seen as an important factor in fostering communication between families in this way. In addition, many respondents indicate that food is tastier when cooked on an open fire (16) (17). Furthermore, paraffin plays an important role in the sharing of resources and communal cooking in times of financial hardship. This is said to increase community 'spirit' between households. Another reason cited is the sexist perception that the presence of electricity in the home makes women lazy. Men reported that with electricity, women would become lazy with doing housework that they should be doing. They were thus hesitant to allow women to use electricity for all household energy requirements (16).

Consequently, development debates in relation to energy provision in developing countries have started to reflect criticism of large-scale technical interventions due to their unsustainable nature. In recent times, there have been calls for the development of relatively cheap strategies, which support or build on the practices of households themselves to reduce their exposure to indoor air pollution. That is, interventions that build on the indigenous household knowledge of indoor air 
pollution and practices used to reduce exposure to it (18).

In the field of indoor air pollution, is behaviour change the answer to the question posed at the beginning of the paper: how can we improve people's health without necessarily increasing their wealth?

The answer to the question, at this stage, is unclear mainly because not much is known, on a global level, of the effectiveness of behaviour change to reduce childhood exposure to IAP. Apart from a few studies that have used education strategies as part of broader programmes to reduce ALRIs (19)(20)(21)(22), very little is known about the effectiveness of behavioural interventions to reduce childhood exposure to the dangerous pollutants produced by the indoor burning of wood, coal and paraffin (23).

The lack of information in this regard is so pronounced that a recent Environmental Health Project (EHP) publication, after careful consideration, deferred to include the issue of behaviour to prevent ALRI because, "the effectiveness of behaviours to reduce exposure to indoor air pollution is largely untested" (Favin et al, 1999, p. 9).

In response to the paucity of information in this regard, the South African Medical Research Council together with the CHANGE project have initiated a study, started in July 2001, to determine whether behaviour change can reduce childhood exposure to indoor air pollution.

\section{METHODOLOGY FOR THE STUDY OF BEHAVIOUR CHANGE TO REDUCE CHILD EXPOSURE TO INDOOR AIR POLLUTION IN SOUTH AFRICA.}

The overall aim of the study is to design, implement and evaluate a behavioural intervention to reduce childhood exposure to indoor air pollution.

\subsection{Phase one}

\subsubsection{Aims}

Because not enough is known about what people are actually doing and the factors influencing behaviours, the specific objectives of phase 1 are:

To describe all of the fuel practices that might have an effect on child exposure to IAP and respiratory health.

To classify those practices as potentially positive or negative.
To describe and understand how practices may differ between a highALRI group and a low-ALRI group.

To understand the factors that influence the positive and negative practices.

To make recommendations as to which negative practices need to be improved and in what ways.

\subsubsection{Subjects}

72 (36 low ALRI and 36 high ALRI) care givers/mothers who look after a child less than 5 years old.

\subsubsection{Methods}

Qualitative, exploratory study design using observations to identify fuel use practices and semi structured interviews to identify factors that influence practices at the household level with 20 low ALRI households and 20 high ALRI households. Focus group discussions will be conducted with a further 16 high ALRI and 16 low ALRI research participants to determine the factors influencing fuel use practices in relation to child health at the community level. Data will be analysed using a thematic analysis.

The recommendations outlined in phase 1 will inform a behavioural intervention that will be tested in phase 2 using a quasi-experimental study design.

\subsection{Phase two}

\subsubsection{Aims}

To design, implement and evaluate a behavioural intervention to reduce child exposure to IAP.

\subsubsection{Subjects}

Two communities (still under consideration) situated in close proximity to those in phase 1 will be selected as study sites. One will serve as the intervention community and one the control. It is envisaged that for sufficient power, 60 households will be included in the intervention and control communities respectively $(\mathrm{N}=120)$.

\subsubsection{Methods}

Phase 2 will be informed by a quasi-experimental, evaluation study design. Baseline information will be collected in both communities using 3 outcome variables, practices, personal exposure measurements $\left(\mathrm{PM}_{10}\right.$ and $\left.\mathrm{CO}\right)$ and ALRI prevalence. The intervention will be implemented in the intervention community. 
Using 3 post-intervention monitoring points with 2 months between each monitoring, phase 2 will seek to determine:

a) If the intervention changes targeted negative practices towards protective practices (and for how long) in the intervention community compared to the control community.

b) If the improved practices decrease child exposure to $\mathrm{PM}_{10}$ and $\mathrm{CO}$ and for how long in the intervention community compared with the control community.

c) If the intervention decreases the prevalence of child ALRI in the intervention community compared with the control community.

\section{CONCLUSION}

This paper has attempted to highlight the role that behaviour change interventions might play in the reduction of childhood exposure to IAP in the search for cheaper, more sustainable interventions.

It has also attempted to highlight the paucity of information available in this neglected field. By presenting the methodology of the South African study, it is hoped to foster studies of this kind in other settings in South Africa and, indeed, around the world.

\section{REFERENCES}

(1) Smith, K. R. (1987). Biofuels, air pollution and health. New York: Plenum Press

(2) Bruce, N., Rogelio, P., Albalak, R. (2000). Indoor air pollution in developing countries: a major environmental and public health challenge. Bulletin of the World Health Organisation, 78 (9), 1078-1092.

(3) Engel, P., Hurtado, E., Ruel, M. (1988). Smoke exposure of women and young children in highland Guatemala: prediction and recall accuracy. Human Organisation, 54, 408-417.

(4) Kammen, D., \& Ezzatti, M. (2001). Acute respiratory infection and indoor air pollution from biomass combustion in Kenya: an exposure-response study. The Lancet, 358, 619-624.

(5) Mathee, A, Rollin, H and Bruce, N. (2000). Electrification and pneumonia in young children in rural areas of South Africa. (Unpublished Medical Research Council study).
(6) Albalak, R. (1997). Cultural practices and exposure to particles pollution from indoor biomass cooking: effects on respiratory health and nutritional status among the Aymara Indians of the Bolivian Highland (doctoral dissertation), University of Michigan.

(7) Anon (1992). Indoor air pollution and acute respiratory infections in children. The Lancet, 339, 396-7.

(8) Smith, K. R., Samet, J. M., Romieu, I., Bruce, N. (2000). Indoor air pollution in developing countries and acute lower respiratory infections in children, Thorax, 55, 518-532.

(9) Von Schirnding, Y., Yach, D. \& Klein, M. (1991). Acute Respiratory Infections as an important cause of childhood deaths in South Africa, South African Medical Journal, 80 (2), 79-82.

(10) Kossove, D. (1982). Smoke filled rooms and lower respiratory disease in infants, South African Medical Journal, April, 62224.

(11) Terblanche, P. (1998). Vaal Triangle air pollution health study. Pretoria: MRC

(12) Bailie, R. S., Pilotto, L. S., Ehrlic, R. I., Mbuli, S., Truter, R, Terblanche, P. (1999). Poor urban environments: use of paraffin and other fuels as sources of indoor air pollution. Journal Of Epidemiology And Community Health, 53, 585-6.

(13) Wentzel, M. (1998). Recommendations on electricity supply options for the rural poor. Energy and Development Research centre, University of Cape Town: unpublished manuscript.

(14) Medical Research Council \& ESKOM (1998). Electrification and health. The South African experience. Pretoria: MRC.

(15) Mehlwana, M \& Qase (1999). The contours of domesticity, energy consumption and poverty: the social determinants of energy use in low-income urban households. Energy and Development Research Centre, University of Cape Town. Unpublished report. Report number EO9612.

(16) Banks, L., Mlomo, B. \& Lujabe, P. (1996). Social determinants of energy use in lowincome households in metropolitan areas (Eastern Cape). Pretoria: South African Government Chief Directorate: Energy.

(17) White, C. F., Cranckshaw, O., Mafokoane, T. \& Meintjies, H. (1996). Social determinants of energy use in low-income households in metropolitan areas (PWV). 
Unpublished report. Report number E09423

(18) Bruce, N. \& Doig, A. (2000). Health and household energy - the need for better links between research and development. Boiling Point, 44, 7-10.

(19) Lye, M. S., Nair, R. C., Choo, K. E., Kuar, H., Lair, K. P. (1996). Acute respiratory tract infection: a community-based intervention, Journal of Tropical Pediatrics, 42 (3), 138-43.

(20) Pandey, M. R., Sharma, P. R., Ghubhaju, B. B., Shakya, G. M., Neupane, R. P., Gautam, A., Shrestha, I. B. (1989). Impact of a pilot acute respiratory infection (ARI) control programme in a rural community of the hill region of Nepal, Annals of Tropical Paediatrics, 9 (4), 212-20.
(21) Bang, A. T., Bang, R. A., Tale, O., Sontakke, P., Solanki, J., Wargantiwar, R., Kelzarkar, P. (1990). Reduction in pneumonia mortality and total childhood mortality by means of community-based trial in Gadchiroli, India, Lancet, 336 (8709), 201-6.

(22) Mtango, F. D. (1986). Acute respiratory infections in children under five years. Control project in Bagamoyo District, Tanzania, Transactions of the Royal society of Tropical Medicine and Hygiene, 80 (6), 851-8.

(23) Favin, M., Yacoob, M., Bendahmane, D. (1999). Behavior first: a minimum package of environmental health behaviours to improve child health. Washington: EHP. 